\title{
Relacionando capital intelectual, gestão do conhecimento e sustentabilidade: um modelo conceitual
}

\author{
Leandro da Silva Nascimento Doutorando em Administração. Universidade Federal do Rio Grande do Sul (UFRGS) - Brasil. \\ lesnasc@gmail.com \\ João Henriques de Sousa Júnior Doutorando em Administração. Universidade Federal de Santa Catarina (UFSC) - Brasil. \\ sousajunioreu@hotmail.com
}

\section{RESUMO}

Recentemente, alguns temas têm sido aprofundados na pesquisa em administração, como capital intelectual, gestão do conhecimento e sustentabilidade. Entretanto, não se identificam na literatura discussões acerca da relação entre estes temas. Atentando-se para tal relação, este ensaio teórico objetiva discutir como o capital intelectual e a gestão do conhecimento contribuem para a adoção da sustentabilidade nas organizações. Da discussão, emerge um modelo conceitual com base em três proposições teóricas que demonstram: (i) a relação mútua entre capital intelectual e gestão do conhecimento e entre suas dimensões; (ii) a existência de relação positiva entre as dimensões do capital intelectual e a adoção da sustentabilidade; e (iii) a presença de relação positiva entre processos de gestão do conhecimento e a adoção da sustentabilidade. Este estudo possui relevância tanto para as organizações que almejam adotar práticas de sustentabilidade quanto para as que querem melhorar a lucratividade por meio do capital intelectual e da gestão do conhecimento.

Palavras-chave: Capital Intelectual. Gestão do Conhecimento. Sustentabilidade.

\section{Relating intellectual capital, knowledge management and sustainability: a conceptual model}

\begin{abstract}
Recently, some themes have been deepened in management research, such as intellectual capital, knowledge management and sustainability. However, discussions about the relationship between these themes are not identified in the literature. Considering this relationship, this theoretical essay aims to discuss how intellectual capital and knowledge management contribute to the adoption of sustainability in organizations. From the discussion, a conceptual model emerges based on three theoretical propositions that demonstrate: (i) the mutual relationship between intellectual capital and knowledge management and its dimensions; (ii) the existence of a positive relationship between the dimensions of intellectual capital and the adoption of sustainability; and (iii) the presence of a positive relationship between knowledge management processes and the adoption of sustainability. This study has relevance both for organizations that aim to adopt sustainability practices and those that want to improve profitability through intellectual capital and knowledge management.
\end{abstract}

Keywords: Intellectual Capital. Knowledge management. Sustainability. 


\section{INTRODUÇÃO}

O aumento da competição global, a necessidade por aperfeiçoamento dos processos produtivos e a forte pressão por qualidade, levam as organizações a inovarem em seus processos produtivos para satisfazer os consumidores e demais stakeholders. É nesse novo cenário que as organizações passam a entender a importância dos ativos intangíveis como indutores de diferenciação, o que gera aumento de lucratividade e valor de marca para as empresas. Pois para Kotler e Keller (2012, p. 35), "a missão de qualquer negócio é fornecer valor ao cliente, sem abrir mão do lucro".

Assim, as organizações que almejam o sucesso apoiam-se em ativos e recursos intangíveis para a geração de valor aos clientes, principalmente por meio do capital intelectual e da gestão do conhecimento. 0 capital intelectual é utilizado como gerador de riqueza, onde aspectos como conhecimento e informação são essenciais para o processo de inovação e criatividade das organizações. E como afirma Rezende (2002, p.78), "o principal foco gerador de riqueza não é mais o trabalho manual, e sim o intelectual".

0 capital intelectual é composto por fatores humanos e fatores internos e externos à organização, sendo que em cenários competitivos, os talentos compõem a peça fundamental para a conquista do sucesso empresarial. Igualmente, é por meio dos colaboradores que o conhecimento é disseminado e compartilhado dentro e fora das organizações, fluindo do nível individual até a formação do conhecimento organizacional. Logo, as organizações passaram a adotar práticas e métodos para gerir um recurso tão vantajoso como 0 conhecimento. Por isso,

as grandes mudanças nos cenários de atuação das empresas, tanto públicas quanto privadas, em especial nesta Era da Informação e Conhecimento, nos permitem imaginar que uma fonte de vantagem competitiva nas empresas é seu ativo intangível 'conhecimento', e a efetiva gestáo e aplicaçáo deste ativo na expectativa de sua conversão em resultados (Francini, 2002, p. 03).

Tanto o capital intelectual quanto a gestão do conhecimento têm conquistado importante posição nas organizações, principalmente na adoção de estratégias sustentáveis. Além destes, outro aspecto possui forte influência nas organizações, a sustentabilidade. Em cenários competitivos, as empresas precisam atender às demandas externas para manterem-se competitivas e uma dessas demandas está na atuação das empresas em ações sociais e ambientais.

A sustentabilidade ressalta a importância da ação das empresas e do comprometimento destas não apenas com o lucro, mas com a satisfação e a manutenção de recursos ambientais e sociais, gerando uma interdependência entre empresa e sociedade. E como afirmam Savitz e Weber (2007, p. 02), "sustentabilidade, na prática, pode ser encarada como a arte de fazer negócios num mundo interdependente".

0 capital intelectual e a gestão do conhecimento vêm sendo discutidos nos estudos organizacionais como relevantes para as novas realidades vivenciadas pelas empresas, principalmente acerca dos avanços tecnológicos e de comunicação. Contudo, não se identifica na literatura pesquisada até este momento, discussões acerca da relação entre capital intelectual, gestão do conhecimento e a sustentabilidade.

Desta forma, há de se questionar, como as empresas podem alavancar suas ações de sustentabilidade, garantindo a preservação de recursos ambientais, contribuindo para o desenvolvimento das sociedades e cumprindo seu papel principal: 'geração de lucro', com base na utilização do capital intelectual e da gestão do conhecimento neste processo? Assim, o presente artigo objetiva discutir como o capital intelectual e a gestão do conhecimento contribuem para a adoção da sustentabilidade nas organizações.

Acerca dos procedimentos metodológicos, este estudo é caracterizado como um ensaio teórico, pois aborda um processo reflexivo que busca estabelecer relacionamentos e propor discussões (Silva \& Cândido, 2014) que clarificam e embasam o debate acerca do relacionamento entre sustentabilidade, capital intelectual e gestão do conhecimento. Desta forma, "no ensaio teórico a orientação é dada não pela busca das respostas e afirmações verdadeiras, mas pelas perguntas que orientam os sujeitos para as reflexões mais profundas" (Meneghetti, 2011, p. 321).

Ademais, a pesquisa consiste numa análise de abordagem qualitativa e possui caráter teórico, baseando-se em revisão narrativa da literatura. A revisão narrativa é adotada para descrever o estado da arte 
de determinado assunto, sob o ponto de vista teórico ou contextual (Botelho, Cunha, \& Macedo, 2011; Rother, 2007) e não costuma fornecer os métodos utilizados na busca das referências e nem as fontes das quais foram retiradas, assim como, não apresenta os critérios utilizados na avaliação e seleção dos trabalhos (Bernardo, Nobre, \&J anete, 2004; Botelho et al., 2011). Assim, explora-se uma breve revisão narrativa da literatura acerca do capital intelectual, da gestão do conhecimento e da sustentabilidade a fim de compreender o sentido de cada conceito e os aspectos que possuem em comum para embasar a discussão deste estudo.

Estruturalmente, além desta introdução, este estudo apresenta a revisão da literatura que embasa os conceitos abordados, ao ponto que gera uma discussão sobre o relacionamento entre estes conceitos e incita proposições teóricas advindas desta discussão e, por fim, suscita considerações. Destarte, este estudo possui relevância tanto para as organizações que almejam implementar a ad oção da sustentabilidade quanto para as que querem melhorar a geração de riqueza por meio do capital intelectual e da gestão do conhecimento.

\section{FUNDAMENTAÇÃO TEÓRICA}

Nesta seção são elencadas relevantes contribuições teóricas acerca dos conceitos que compõem este estudo. Dessa forma, subdivide-se esta seção em três temáticas - capital intelectual; gestão do conhecimento; e sustentabilidade, conforme disposição a seguir.

\subsection{Capital intelectual - fator de sucesso organizacional}

As organizações necessitam adaptar-se às exigências do mercado ao qual se inserem para manteremse competitivas. Passando desde a fase da utilização dos colaboradores como mera fonte de força física e com baixo uso da tecnologia, até os dias atuais, onde é preciso adaptar-se ao uso intensivo da tecnologia e cujos colaboradores são fontes de capacidades e habilidades cognitivas.

Com as máquinas executando o serviço físico, principalmente nas indústrias produtivas, a mão de obra passou a ter outras funções essenciais, com foco no raciocínio e na utilização do conhecimento. Desta forma, os indivíduos organizacionais passam a desenvolver o saber individual, focalizando-o de forma a alavancar as vantagens competitivas das organizações. Assim, uma das bases de pesquisa sobre gestão do conhecimento nas organizações enfoca o capital intelectual (Cassol, Gonçalo, \& Ruas, 2016).

Por definição, o capital intelectual engloba atividades e processos baseados no conhecimento, que contribuem para a inovação, a criação de valor, vantagens competitivas e benefícios de longo alcance para as empresas, o que, também, acaba por agregar valor para os stakeholders (Sardo, Serrasqueiro, \& Alves, 2018).

$\mathrm{Na}$ era do conhecimento, o capital intelectual representa grande parte do valor de um produto, constituindo uma atividade importante para organizações que querem ser eficientes no mercado e, assim, obter vantagem competitiva sustentável (Gogan, Artene, Sarca, \& Draghici, 2016). Ainda conforme os autores, existe uma relação significante entre capital intelectual e desempenho organizacional.

Indo além, compreende-se que "[...] a gestão do capital intelectual definida como um recurso interno valioso pode contribuir para impulsionar a capacidade de inovação" (Cassol et al., 2016, p. 3), pois a inovação nas organizações é, antes de tudo, uma questão humana (Kianto, Sáenz, \& Aramburu, 2017).

0 capital intelectual é analisado a partir da perspectiva da visão baseada no conhecimento, a qual é fundamentada nos preceitos da visão baseada em recursos, da teoria da aprendizagem organizacional e da teoria organizacional (Acedo, Barroso, \& Galan, 2006). Sendo que, nas últimas décadas, a literatura de gestão utilizou o conceito de capital intelectual para entender de qual forma o conhecimento funciona como um ativo-chave na criação de valor para as organizações (Kianto et al., 2017). Ainda conforme estes autores, o capital intelectual constitui a soma de todos os recursos intangíveis e relacionados ao conhecimento que uma organização usa para criar valor.

O capital intelectual é composto por três categorias principais: capital humano, capital estrutural ou organizacional e capital relacional ou social (Kianto et al., 2017; Rezende, 2002; Sardo et al., 2018; Sveiby, 1998). Assim, o conhecimento é acumulado: (i) pela empresa por meio dos indivíduos - capital humano - com base em talentos, habilidades e conhecimentos dos funcionários; (ii) pelos relacionamentos e redes - capital 
social/relacional - com criação e manutenção de relações com stakeholders, e (iii) pela sistematização do conhecimento por processos e sistemas organizacionais - capital organizacional/estrutural - que envolvem capacidades, cultura, patentes, direitos autorais, marcas registradas, bancos de dados etc. (Sardo et al., 2018; Subramaniam \& Youndt, 2005).

Conjuntamente, estas três formas de capital - humano, relacional e estrutural - compõem o capital intelectual (Runyan, Droge, \& Swinney, 2008). Sobre esta relação, depreende-se que o capital humano é o elemento mais significativo para o capital intelectual, porque uma empresa não pode realizar nada - incluindo inovação e o alcance de ativos tangíveis ou intangíveis - sem a ação humana (Kianto et al., 2017; Sveiby, 1998).

\begin{abstract}
A ideia fundamental da teoria do capital humano é que o trabalho, mais do que um fator de produção é um tipo de capital: capital humano. Esse capital é tão mais produtivo quanto maior for sua qualidade. Essa qualidade é dada pela intensidade de treinamento científico-tecnológico e gerencial que cada trabalhador adquire ao longo de sua vida. A qualidade do capital humano não apenas melhora o desempenho individual do trabalhador - tornando-o mais produtivo - como é um fator decisivo para gerar riqueza, crescimento econômico do país e de equalização social (Motta, 2008, p. 03).
\end{abstract}

Isto levou ao reconhecimento e a valorização dos colaboradores, passando as organizações a tratálos como uma forma de capital - o capital humano. Assim, no contexto da teoria da visão baseada em recursos, o capital humano deve ser considerado um fator central para a competição das organizações (Gamerschlag, 2013). Com base nisto, o capital intelectual possui relação positiva com o desempenho organizacional, sendo que a inovação possui papel mediador entre o capital intelectual e o desempenho organizacional (McDowell, Peake, Coder, \& Harris, 2018). Assim, o capital intelectual constitui a matéria intelectual, como o conhecimento, a informação, a propriedade intelectual e experiências que podem ser utilizadas para gerar riqueza (Stewart, 1998).

Dessa forma, a globalização e os avanços tecnológicos impulsionam o desenvolvimento de empresas do conhecimento, capazes de serem inovadoras e criativas, baseando-se não apenas em ativos tangíveis como centro de geração de valor, mas também em ativos intangíveis, capazes de gerar vantagem competitiva. Dessa forma, o "capital intelectual é, enfim, o conhecimento existente em uma organização que pode ser usado para criar uma vantagem diferenciada" (Rezende, 2002, p. 78), sendo que o desenvolvimento, a acumulação e a distribuição deste conhecimento são facilitados pelo desenvolvimento do capital intelectual (McDowell et al., 2018).

Os colaboradores são a chave para o sucesso das organizações que necessitam de sua expertise, do seu conhecimento, das suas habilidades e competências individuais para a formulação de produtos e serviços inovadores e criativos, garantindo assim, a satisfação e fidelização dos consumidores. Assim, "[...] quando o conhecimento tornou-se a principal matéria-prima e resultado da atividade econômica, a inteligência organizacional - pessoas inteligentes trabalhando de formas inteligentes - deixou de ter um papel coadjuvante e passou a assumir o papel principal" (Stewart, 1998, p. 52).

As estruturas físicas e maquinários são importantes para o sistema produtivo e a criação de trabalho nas organizações. No entanto, "na era do capital intelectual, as partes mais valiosas desses trabalhos tornaramse essencialmente tarefas humanas: sentir, julgar, criar, desenvolver relacionamentos" (Stewart, 1998, p. 47). Essa percepção leva ao entendimento de que as empresas que compreendem a importância de seus funcionários para o seu sucesso terão maior preocupação em gerar meios de impulsionar o desenvolvimento desses indivíduos, que de forma direta, investirão na aplicação do conhecimento próprio para alavancar processos criativos e rentáveis a estas organizações.

$\mathrm{Na}$ verdade, ocorre um processo de simbiose, onde a associação entre as organizações e seus indivíduos gera vantagens para ambos. Desta forma, o capital intelectual é reconhecido como um recurso estratégico para as empresas (Cassol et al., 2016), sendo possível afirmar que a criação de valor nas organizações é proveniente do alinhamento estratégico da gestão do conhecimento em torno dos processos (Costa \& Rezende, 2018). Assim, há de se destacar o papel da gestão do conhecimento para a eficiência e eficácia do capital intelectual. 


\subsection{Gestão do conhecimento - o trunfo das organizações}

O capital intelectual é fundamentado no conhecimento, sendo este um recurso advindo do saber dos colaboradores, dos grupos ou mesmo da organização. Esse conhecimento precisa ser gerido, por meio de estratégias de gestão do conhecimento, capazes de neutralizar as ameaças e aproveitar as oportunidades, agregando valor à estratégia organizacional. Nesse caso, os gestores/líderes são essenciais no desenvolvimento de práticas de disseminação e compartilhamento do conhecimento, sendo responsáveis também pelo comprometimento de sua amplitude de controle com as causas organizacionais.

O compartilhamento do conhecimento é definido como o grau em que os funcionários compartilham seus conhecimentos adquiridos com outras pessoas (Teh \& Yong, 2011). Se os funcionários não compartilham seus conhecimentos na organização, não contribuem para a geração de vantagem competitiva (Curado, Oliveira, Maçada, \& Nodari, 2017). Isto posto, depreende-se que "o conhecimento tornou-se a principal ferramenta competitiva para as empresas. Assim como o conhecimento é considerado o recurso estratégico mais importante, a gestão do conhecimento é considerada crítica para o sucesso da empresa" (MarteloLandroguez \& Cepeda-Carrión, 2016, p. 423).

O conhecimento pode estar implícito e existir nas mentes dos funcionários da organização ou pode ser explícito e especificado nos documentos relevantes de regras e regulamentos da organização. Em comparação com o conhecimento explícito, o conhecimento implícito é mais vantajoso para estabelecer a vantagem competitiva sustentada de uma organização, porque é raro e difícil de ser imitado ou substituído (Liao, Chen, Hu, Chung, \& Yang, 2017, p. 1435).

Embora a dualidade entre conhecimento tácito e explícito seja difundida na literatura, não revela o tipo de comportamento envolvido no compartilhamento do conhecimento (Curado et al., 2017). Independente da forma constitutiva, o conhecimento tem sido amplamente reconhecido como um dos ativos mais importantes em uma organização, precisando ser gerenciado com sucesso para obtenção de vantagem competitiva (Serenko, Bontis, \& Hull, 2016).

Assim, as empresas buscam formas de fortalecer suas bases de pesquisa e de contribuir para 0 desenvolvimento de conhecimento, mantendo-o eficiente para que possa ser utilizado de forma eficaz (Liao et al., 2017). Cabe ressaltar o papel da inovação nesse processo, sendo que "[...] qualquer inovação implica o desenvolvimento de novos conhecimentos tanto como insumo (por exemplo, novas ideias, conceitos, protótipos, etc.) como um resultado (ou seja, a novidade produzida)" (Kianto et al., 2017, p. 11).

Com foco na inovação e para evitar imitação ou duplicação por parte dos concorrentes, as empresas geralmente adquirem ou aprendem novos conhecimentos introduzidos a partir de uma unidade fora da organização, de forma a integrar o novo conhecimento ao já existente, como forma de desenvolver o conhecimento que pertence exclusivamente à organização (Liao et al., 2017). Por meio da aquisição de novos conhecimentos e da atualização do conhecimento existente, uma organização pode ter melhor desempenho de aprendizado e inovação e, assim, desenvolver uma vantagem competitiva sustentável. (Liao \& Hu, 2007).

É necessário enfatizar que a criatividade tangencia a geração de ideias, enquanto a inovação referese a sua operacionalização (Gurteen, 1998). Ainda conforme este autor, criatividade e inovação dizem respeito ao processo de criação e aplicação de novos conhecimentos. Desta forma, "a importância da criatividade no contexto organizacional e, para o conhecimento, dá-se pelo início do processo de inovação, uma vez que se faz necessário colocar as ideias em ação" (Wojahn, Rados, \& Trzeciak, 2017, p. 215).

No âmbito das questões que cercam o uso do conhecimento no contexto organizacional, quatro aspectos são comumente pesquisados: (i) as estratégias de conhecimento; (ii) os processos de gestão do conhecimento; (iii) os capacitores da gestão do conhecimento; e (iv) as práticas de gestão do conhecimento (Shahzad, Bajwa, Siddiqi, Ahmid, \& Sultani, 2016), sendo possível afirmar que os processos de gestão do conhecimento possuem certo destaque nos estudos sobre conhecimento nas organizações.

Acerca dos processos, "[...] quatro dimensões-chave destacam-se como afetando os processos de gestão do conhecimento: criação de conhecimento, transferência de conhecimento, armazenamento / recuperação de conhecimento e aplicação de conhecimento" (Martelo-Landroguez \& Cepeda-Carrión, 2016, 
p. 423). Conforme estes autores, os processos de gestão do conhecimento são responsáveis pelo aumento da criação e da captura de valor nas empresas, sendo possível afirmar que há uma relação positiva entre gestão do conhecimento e criação de valor, como também, entre a criação e a captura de valor.

A criação do conhecimento pode ser compreendida como a acumulação de conhecimento na organização, resultante de sua capacidade de absorver conhecimento externo (Martelo-Landroguez \& Cepeda-Carrión, 2016). Transferência de conhecimento refere-se à troca de conhecimento entre a fonte e o destinatário (Radaelli, Mura, Spiller, \& Lettieri, 2011), constituindo-se no ato de tornar o conhecimento disponível para outros dentro da organização (Ipe, 2003). Entretanto, cabe ressaltar que este processo deve ser compreendido para além de uma simples relação de transferência, ou seja, deve ser considerado como uma forma de compartilhamento. Pois se caracteriza pela necessidade de interação entre o emissor e 0 receptor, sendo que este processo além de transferir gera novos conhecimentos à medida que os atores envolvidos interagem, constroem ou reconstroem os significados e, assim, geram conhecimento aprimorado.

Acerca do armazenamento e da recuperação do conhecimento, são mecanismos que permitem com que os membros da organização tenham acesso rápido e fácil às informações (Chou, Chang, Cheng, \& Tsai, 2007). Assim, todos os membros de uma empresa devem ter acesso à base de informações para obter 0 conhecimento necessário para ajudá-los na tomada de decisão e na condução do trabalho (MarteloLandroguez \& Cepeda-Carrión, 2016).

Não há muitos estudos na literatura acerca da aplicação do conhecimento (Martelo-Landroguez \& Cepeda-Carrión, 2016), sendo este processo descrito como a utilização atual do conhecimento na organização (Ipe, 2003). A aplicação do conhecimento implica a utilização do conhecimento gerado na fase de criação e retido nas fases de transferência e armazenamento ou recuperação (Martelo-Landroguez \& Cepeda-Carrión, 2016).

É possível afirmar que os processos de gestão do conhecimento são influenciados pelo contexto organizacional (Shahzad et al., 2016), sendo necessário compreender o setor de atuação, as características ambientais e as premissas da organização para melhor condução do processo de gestão do conhecimento.

No entendimento de Tonet $(2008$, p. 47$)$ "as pessoas são a fonte do conhecimento, que adquirem por meio da aprendizagem, e que, transferido para as organizações, provocam mudanças e produzem a aprendizagem organizacional". Portanto, para manter os talentos e para permitir o processo de inovação organizacional, os colaboradores precisam ser incentivados a aprender continuamente. A aprendizagem pode ocorrer no âmbito pessoal, ou seja, fora da organização ou dentro desta. Os gestores possuem um papel importante na ado ção de práticas de aprendizagem dentro das organizações, pois nesse contexto, a figura do líder e seu perfil funcional assumem novas configurações, tal qual a capacidade de construir uma visão compartilhada, de trazer à tona modelos mentais vigentes e de incentivar padrões mais sistêmicos de pensamento (Angeloni, 2003).

$\mathrm{Na}$ era do conhecimento, os líderes são os agentes que impulsionam o desenvolvimento do capital intelectual, principalmente com ações que estimulam a criação e adoção de práticas que satisfaçam as necessidades e os desejos dos colaboradores, que vão desde a remuneração até o reconhecimento dentro e fora da empresa. Existe uma diferença básica entre simples gestores e gestores do conhecimento:

Nas organizações tradicionais, os gerentes dizem aos funcionários exatamente como as coisas devem ser feitas e depois os vigiam para garantir o cumprimento do comando. Já nas organizações do conhecimento, os gerentes (líderes) explicam os resultados necessários e ajudam seus subordinados a descobrirem como farão o trabalho (Pereira, 2003, p. 16).

Os líderes são responsáveis pelo desenvolvimento de seus subordinados e para tal, precisam demonstrar que são capazes, sendo referência para os demais colaboradores. Assim, os líderes buscam facilitar o processo de compartilhamento e gestão do conhecimento, por meio de práticas de desenvolvimento e reconhecimento de seus subordinados. Mesmo que os gerentes sejam especialistas em suas áreas departamentais, como finanças, marketing e produção, é notório e imprescindível que possuam também a função de gerir os recursos humanos, pois a organização é composta por capital humano, em cada departamento e em cada amplitude de controle. 
As empresas do conhecimento passam a reconhecer os seus funcionários não mais como um capital a ser explorado até seu esgotamento, mas como parte integrante e essencial da organização, merecendo respeito e reconhecimento. Portanto, a preocupação com o desenvolvimento do capital intelectual e a gestão do conhecimento passa a ocupar participação essencial na estratégia organizacional, seja esta no nível de negócio ou corporativa.

Ademais, é preciso compreender que as organizações que vivenciam o processo de globalização estão se adaptando às exigências externas, sejam estas a nível econômico, social ou ambiental e para lidar com essas exigências, precisam integrar em suas políticas e práticas, aspectos que as permitam atenderem a essas necessidades de forma a não perder participação de mercado e gerando ao mesmo tempo vantagem competitiva. Ou seja, é preciso igualar o crescimento organizacional com o crescimento da sociedade em seus diversos aspectos, visto que interagem e contribuem para a manutenção dos mercados. Portanto, o investimento em capital intelectual e na gestão do conhecimento na estratégia das organizações é essencial para que as empresas possam atender às exigências externas.

Os fatores social e ambiental são de extrema relevância e estão adquirindo maior importância no âmbito organizacional. Com isso, as organizações buscam desenvolver práticas e ações no âmbito da sustentabilidade. Grandes são as pressões externas para que as empresas adotem práticas de produção que diminuam ou eliminem a poluição ou que contribuam para o desenvolvimento das comunidades ao entorno das empresas. Para tal, verifica-se que as empresas passaram a adotar práticas de sustentabilidade.

\subsection{Compreendendo a sustentabilidade}

A sustentabilidade é um termo amplamente difundido entre as organizações, principalmente pelas grandes corporações. 0 termo remete a ideia da atuação organizacional aliada à manutenção e sustentação do meio ambiente e da sociedade. Nesse ponto, "empresa sustentável é aquela que gera lucro para os acionistas, ao mesmo tempo em que protege o meio ambiente e melhora a vida das pessoas com quem mantém interações" (Savitz \& Weber, 2007, p. 02).

Além da função primária de gerar lucros aos acionistas, as empresas passam a adotar funções sociais e ambientais, que integradas à estratégia organizacional, conduzem a empresa a alcançar retornos financeiros de forma a manter a satisfação dos consumidores e demais stakeholders. Assim, "sustentabilidade é reconhecimento das necessidades e interesses das outras partes (grupos comunitários, instituições educacionais e religiosas, força de trabalho e público), não esgarçando, mas, ao contrário, reforçando a rede de relacionamentos que as mantém integradas" (Savitz \& Weber, 2007, p. 03).

Depreende-se que o termo desenvolvimento sustentável avançou na discussão teórica, empresarial e governamental, sendo que "o desenvolvimento sustentável é aquele que atende às necessidades do presente sem comprometer a capacidade das gerações futuras satisfazerem as suas próprias necessidades" (Comissão Mundial Para o Meio Ambiente e o Desenvolvimento [CMMAD], 1991, p. 46). Compreende-se que o desenvolvimento sustentável é comumente definido como sendo sustentabilidade (Barbieri \& Silva, 2011), sendo que esta substituição de nomenclaturas vem se desenvolvendo principalmente no campo organizacional. Sobre este aspecto, pode-se afirmar que "há um uso equivocado dos conceitos complementares, mas conceitualmente divergentes - sustentabilidade e desenvolvimento sustentável - na literatura acerca dos estudos organizacionais" (Nascimento, 2018).

Esta distinção é abordada em um trabalho desenvolvido por Feil e Schreiber (2017), que demonstram que a utilização da sustentabilidade como sendo desenvolvimento sustentável é equivocada, visto que são construtos distintos, com suas características conceituais específicas, o que não implica na falta de complementariedade entre estes.

A sustentabilidade é um termo que expressa a preocupação com a qualidade de um sistema que diz respeito à integração indissociável (ambiental e humano), e avalia suas propriedades e características, abrangendo os aspectos ambientais, sociais e econômicos. Essa avaliação realiza-se em determinado ponto estático, como em uma fotografia do sistema, ou seja, sua qualidade naquele instante, apesar de o sistema ser dinâmico e complexo. Assim, a avaliação é operacionalizada por meio de indicadores e/ou 
O desenvolvimento sustentável é analisado como um meio para o alcance da sustentabilidade, sendo que preceitua conciliar a característica parad oxal existente entre a dimensão ambiental - sustentabilidade - e a econômica - desenvolvimento - (Feil \&Schreiber, 2017). Desta forma, pode-se afirmar que a sustentabilidade possui caráter mais amplo que o desenvolvimento sustentável, sendo imprescindível a consideração de ações de longo prazo associadas com medidas de desempenho para sua efetividade (Nascimento, 2018). Com foco no alcance de longo prazo, compreende-se que para ser implementada com efetividade, a sustentabilidade requer tempo (Bansal \& Desjardine, 2014; Seghezzo, 2009). Faz-se necessário enaltecer que uma característica que diferencia a sustentabilidade de outros conceitos similares - exemplo da responsabilidade social corporativa - é seu caráter de análise de trade-offs ao longo do tempo, enquanto a responsabilidade social corporativa não requer consideração de trade-offs (Bansal \& Desjardine, 2014).

0 conceito de sustentabilidade se baseia em um preceito ético e nos desejos expressos para a equidade, sendo que a prosperidade e a proteção do meio ambiente representam posições morais (Stefano \& Laux, 2017). Desta forma, a sustentabilidade precisa se desenvolver com base em preceitos éticos e morais, que são características do processo de educação social, não sendo possível o alcance de metas sustentáveis se estas não são compartilhadas pelos indivíduos. Ainda sobre as limitações, pode-se inferir que "um dos desafios da realização da sustentabilidade é o exame crítico de pressupostos comuns e paradoxos do pensamento de sustentabilidade do mainstream" (Kopnina, 2017, p. 38).

É comum analisar a sustentabilidade como algo inerente às organizações, sendo estas responsáveis por mitigar os problemas sociais e ambientais. Desta forma, não apenas a superprodução, mas também o superconsumo gera impedimentos para o alcance da sustentabilidade (Kopnina, 2017), sendo que o problema do superconsumo pode ser compreendido como uma consequência das ações organizacionais. Desta forma, o consumidor não é o único culpado por consumir, devendo-se compreender que as empresas que se utilizam de ações estratégicas como a propaganda e processos de criação e inovação, são responsáveis por atrair os consumidores, impossibilitando com que estes controlem o desejo por comprar e permitindo, assim, que continuem comprando cada vez mais (Silva, Araújo, \& Santos, 2012). Assim sendo, cabe às organizações impulsionar ações que auxiliem a minimizar os problemas sociais e ambientais advindos do estilo de vida moderno, baseado no consumismo.

Historicamente, a sustentabilidade tem sido abordada com base em três dimensões: a econômica, a social e a ambiental. As dimensões ambiental, social e econômica da sustentabilidade são subsistemas que devem ser desenvolvidos de maneira equilibrada, ou ao menos otimizada (Munck, Galleli, \& Souza, 2012), o que requer a compreensão das três dimensões ou aspectos para melhor desenvolvimento reflexivo acerca dos problemas socioambientais e para impulsionar o desenvolvimento efetivo da sustentabilidade.

Para a efetividade da sustentabilidade, as organizações precisam desenvolver e obter recursos e capacidades que as permitam ter excelência na execução de suas ações. É desse pensamento que a relação entre capital intelectual e gestão do conhecimento emerge para a consolidação de práticas de sustentabilidade na conjuntura organizacional, sendo necessário compreender como se dá essa relação, o que será apresentado a seguir.

\section{ALCANÇANDO A SUSTENTABILIDADE COM BASE NO CAPITAL INTELECTUAL E NA GESTÃO DO CONHECIMENTO: O MODELO CONCEITUAL}

O conhecimento é essencial para o desenvolvimento e sustentação das estratégias organizacionais, estando estreitamente relacionado com o capital intelectual, enquanto que este se relaciona diretamente com o conhecimento, pois são complementares. Desta forma, a gestão do conhecimento por si só não propicia as bases para a criatividade e a inovação, sendo necessário que o capital intelectual atue neste processo, 0 que 
demonstra um caráter relacional, no qual o capital intelectual influencia a manutenção da gestão do conhecimento e a própria gestão do conhecimento exerce influência na desenvoltura do capital intelectual.

Assim, a Figura 1 demonstra a relação existente entre capital intelectual e gestão do conhecimento como sendo mutuamente influenciadora. Indo além, a referida figura também demonstra a relação que tanto o capital intelectual quanto a gestão do conhecimento exercem na adoção da sustentabilidade, podendo-se induzir que a sustentabilidade é alcançada por meio do capital intelectual e da gestão do conhecimento. Esta inferência toma por base as dimensões que sustentam cada um dos construtos - capital intelectual, gestão do conhecimento e sustentabilidade -, pois estas dimensões também se relacionam.

Na gestão do conhecimento, os processos de criação, transferência, armazenamento/recuperação e aplicação do conhecimento são essenciais para o desenvolvimento do capital social, do capital humano e do capital estrutural desenvolvidos no âmbito do capital intelectual. Além disso, as dimensões do próprio capital intelectual também influenciam nas dimensões que compõem o processo de gestão do conhecimento. Assim, demonstra-se a primeira proposição constante na Figura 1:

P1: 0 capital intelectual exerce influência no desenvolvimento dos processos de gestão do conhecimento, enquanto a gestão do conhecimento exerce influência nas dimensões do capital intelectual.

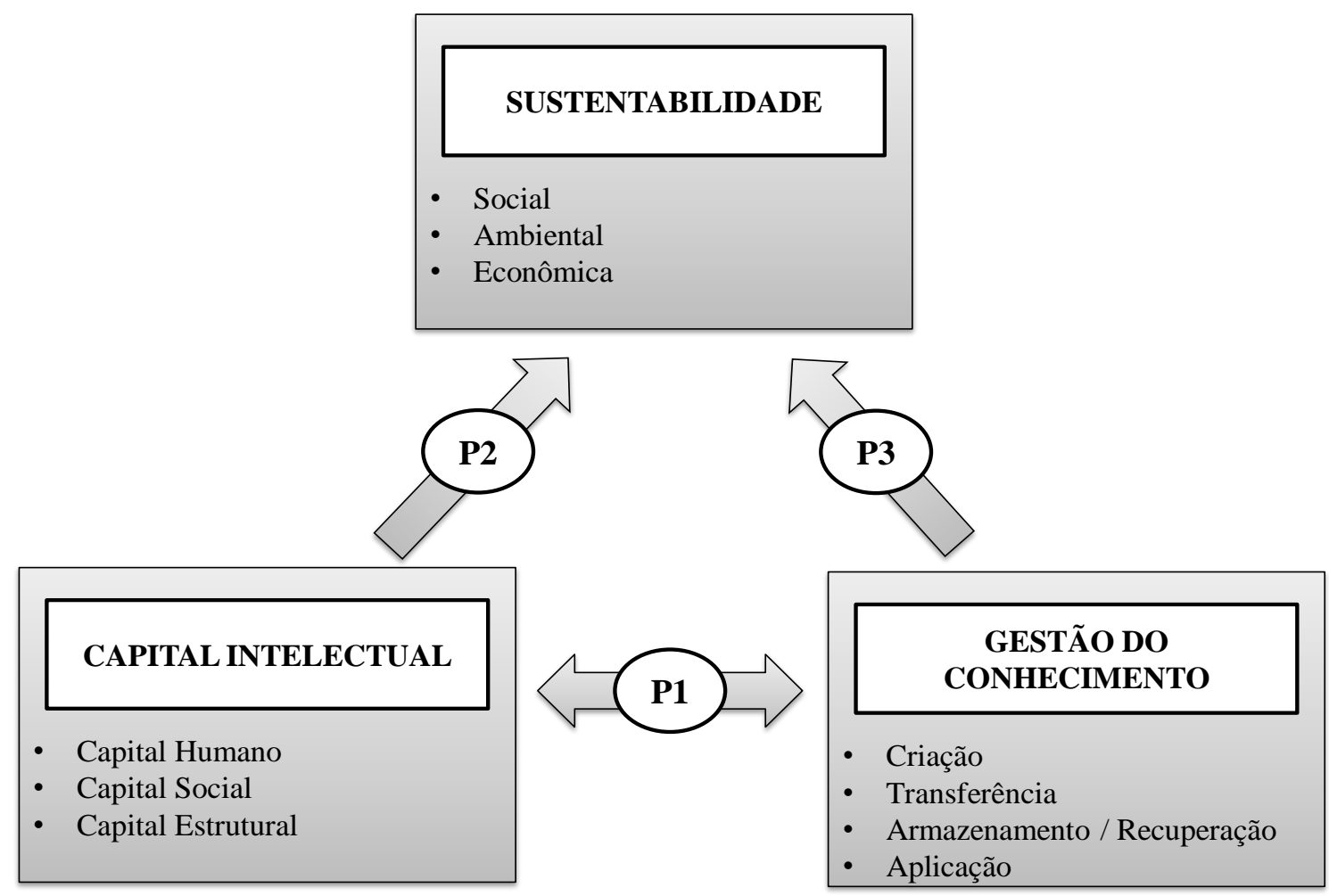

Figura 1. Modelo Conceitual: Relacionando Capital Intelectual, Gestão do Conhecimento e Sustentabilidade

Fonte: Elaboração autoral

Compreende-se que o capital intelectual é fundamental para o alcance da sustentabilidade, pois é por meio dos capitais social, humano e estrutural que as organizações conseguem induzir a criatividade e a inovação nos produtos e serviços que propiciam a minimização de impactos socioambientais negativos. Desta forma, demonstra-se a segunda proposição constante na Figura 1:

P2: As dimensões do capital intelectual exercem influência positiva nas dimensões da sustentabilidade, sendo que o capital intelectual propicia a adoção da sustentabilidade. 
Os processos de criação, transferência, armazenamento/recuperação e aplicação do conhecimento que baseiam a gestão do conhecimento são essenciais para o desenvolvimento de produtos e serviços com foco socioambiental. Por fim, demonstra-se a terceira proposição constante na Figura 1:

P3: A gestão do conhecimento com base em seus processos constitutivos exerce influência positiva na adoção da sustentabilidade - dimensões social, ambiental e econômica - nas organizações.

Estas proposições são defendidas, tendo em vista que o conhecimento é descrito como o único recurso que pode criar uma vantagem competitiva sustentável (Zack, 1999), sendo necessário para a constituição de ações sociais e ambientais efetivas no âmbito organizacional. Além disso, muitos estudos argumentam que a gestão do conhecimento funciona como uma forma de gerar valor superior ao consumidor (Martelo-Landroguez \& Cepeda-Carrión, 2016). Assim, pode-se inferir que a relação entre gestão do conhecimento e sustentabilidade acaba por contribuir com a geração de valor econômico, social e ambiental aos ecossistemas, às comunidades e às próprias organizações.

Destaca-se que a gestão do conhecimento pode afetar as estratégias desenvolvidas em nível global por multinacionais, principalmente acerca da transferência de conhecimento, que ocorre tanto da sede para as subsidiárias quanto destas para aquela - transferência de conhecimento reversa - (Kogut \& Mello, 2017). Desta forma, pode-se supor que a criação de técnicas e de práticas para a sustentabilidade em subsidiárias possam ser replicadas tanto pela sede quanto por outras subsidiárias, demonstrando o papel da gestão do conhecimento neste processo.

Ser capaz de identificar o que os clientes querem de um produto ou serviço também ajuda uma empresa a formular sua proposta de valor (Martelo-Landroguez \& Cepeda-Carrión, 2016), sendo que esta análise se baseia nos capitais social, humano e estrutural que constituem o capital intelectual, e acabam por possibilitar a geração de práticas de sustentabilidade que gerem valor econômico, social e ambiental tanto para os consumidores quanto para outros stakeholders.

Ressalta-se que as pessoas são essenciais para a formulação de práticas e ações em prol da sustentabilidade, pois são as pessoas que vivenciam as realidades e as adversidades sociais e ambientais existentes nas sociedades e, assim, são essenciais para impulsionar ações no âmbito organizacional que mitiguem os impactos negativos tanto para os ecossistemas quanto para as sociedades. Conforme Seghezzo (2009), as pessoas são essenciais para o desenvolvimento da sustentabilidade, não sendo possível focar em ações socio ambientais sem analisar a relação humana neste processo. Assim, o capital intelectual desempenha um forte elo com a sustentabilidade, pois é por meio deste capital que se pode desenvolver as relações sociais e humanas que fortificam os processos de criatividade e inovação em prol da sustentabilidade nas empresas.

Compreende-se que o capital intelectual auxilia no alcance de vantagens competitivas e de benefícios de longo alcance para as empresas, como também, acaba por agregar valor para os stakeholders (Sardo et al., 2018). Assim, é possível afirmar que o capital intelectual possui participação na geração de valor social, ambiental e econômico, estando conectado com a visão de tempo que é essencial para a sustentabilidade como afirmam Bansal e Desjardine (2014) e atua de forma positiva no desempenho organizacional como defendem Gogan, Artene, Sarca e Draghici (2016), o que ressalta a relação do capital intelectual com as três dimensões da sustentabilidade - social, ambiental e econômica.

Assim, o investimento nestas práticas e ações requer o envolvimento dos colaboradores, por meio do comprometimento individual e do desenvolvimento do capital intelectual e da gestão do conhecimento. Pois é com base no capital intelectual e na gestão do conhecimento que as empresas conseguem criar métodos inovadores e criativos. Posto isso, entende-se que as organizações que buscam desenvolver políticas de sustentabilidade precisam se apoiar no capital intelectual e na gestão do conhecimento.

\section{CONSIDERAÇÕES FINAIS}

Reiterando a influência que o conhecimento exerce no desenvolvimento e na sustentação de estratégias no âmbito organizacional, o presente artigo se propôs a fazer uma discussão teórica acerca da relação entre o capital intelectual, a gestão do conhecimento e a sustentabilidade. Esta discussão desenvolveuse de modo a tratar de uma temática pertinente à comunidade científica, proporcionando maior atenção a 
partir de estudos prévios para uma relação ainda não investigada. Proveniente desta articulação teórica foi proposto um modelo conceitual para embasar a análise relacional entre capital intelectual, gestão do conhecimento e sustentabilidade.

A proposição do referido modelo conceitual ressalta a valia que cada um dos construtos discutidos desempenha na ciência da administração, e apresenta relevante contribuição teórica ao campo de estudos da sustentabilidade, destacando um conjunto de relações ainda não exploradas desta com o capital intelectual e a gestão do conhecimento. Isto porque o modelo desenvolvido neste estudo infere, a partir das três proposições de relacionamentos - i) Gestão do Conhecimento e Capital Intelectual; ii) Capital Intelectual e Sustentabilidade; iii) Gestão do Conhecimento e Sustentabilidade - que a sustentabilidade é alcançada por meio dos outros dois construtos.

Dito isto, pode-se concluir que o modelo conceitual proposto reafirma a importância do conhecimento como uma vantagem competitiva sustentável, sendo a gestão do conhecimento uma forma de criar valor para o consumidor; auxilia na formulação de valor para empresas, com base na capacidade de identificar o que os clientes querem de um produto ou serviço; ressalta a importância das pessoas na formulação de práticas e ações em prol da sustentabilidade; compreende o capital intelectual como uma forma de se auxiliar no alcance de vantagens competitivas e benefícios de longo alcance para empresas; e aponta o investimento em práticas e ações com base no desenvolvimento do capital intelectual e da gestão do conhecimento, pois as organizações que buscam desenvolver políticas de sustentabilidade precisam se apoiar nestes dois elementos.

Em termos gerais, e com base em todo o exposto, afirma-se que é possível relacionar o capital intelectual e a gestão do conhecimento com base em uma compreensão mutuamente influenciadora, em que ambos possuem bases que apoiam o desenvolvimento de práticas socioambientais, sendo possível inferir que tanto o capital intelectual quanto a gestão do conhecimento são essenciais para a adoção da sustentabilidade nas organizações.

Como possível limitação à análise deste estudo, entende-se que conhecimento possui características tangíveis e intangíveis, e está envolto tanto na gestão do próprio conhecimento quanto na constituição do capital intelectual, assim, seu efeito sobre outros aspectos pode ser de difícil mensuração (Darroch \& McNaughton, 2003). Com vistas à realização de estudos futuros, se faz necessário um aprofundamento empírico das proposições levantadas neste ensaio teórico, sendo possível analisá-las em distintos lócus de pesquisa, o que pode demonstrar a sustentação do modelo conceitual aqui proposto em diversos setores ou indústrias.

\section{REFERÊNCIAS}

Acedo, F. J., Barroso, C., \& Galan, J. L. (2006). The resource-based theory: dissemination and main trends. Strategic Management Journal, 27(7), 621-636. https://doi.org/10.1002/smj.532

Angeloni, M. T. (Coord.) (2003). Organizações do conhecimento: infra-estrutura, pessoas e tecnologias. São Paulo: Saraiva.

Bansal, P., \& Desjardine, M. R. (2014). Business sustainability: It is about time. Strategic Organization, 12(1), 7078. http://journals.sagepub.com/doi/10.1177/1476127013520265

Barbieri, J . C., \& Silva, D. (2011). Desenvolvimento sustentável e educação ambiental: uma trajetória comum com muitos desafios. Rev. Adm. Mackenzie, 12(3), 51-82. http://dx.doi.org/10.1590/S167869712011000300004

Bernardo, W. M., Nobre, M. R. C., \& J anete, F. B. (2004). A prática clínica baseada em evidências. Parte II: buscando as evidências em fontes de informação. Revista da Associação Médica Brasileira, 50(1), 104-108. http://dx.doi.org/10.1590/S0104-42302004000100045

Botelho, L. L. R., Cunha, C. C. A., \& Macedo, M. (2011). 0 método da revisão integrativa nos estudos organizacionais. Gestão e Sociedade, 5(11), 121-136. https://doi.org/10.21171/ges.v5i11.1220

Cassol, A., Gonçalo, C. R., \& Ruas, L. R. (2016). Redefining the Relationship between Intellectual Capital and Innovation: The Mediating Role of Absorptive Capacity. Brazilian Administration Review, 13(4), 1-25. http://dx.doi.org/10.1590/1807-7692bar2016150067 
Chou, T.-C., Chang, P.-L., Cheng, Y.-P., \& Tsai, C.-T. (2007). A path model linking organizational knowledge attributes, information processing capabilities, and perceived usability. Information \& Management, 44(4), 408-417. https://doi.org/10.1016/j.im.2007.03.003

Comissão Mundial Para o Meio Ambiente e o Desenvolvimento. (1991). Nosso Futuro Comum. Fundação Getúlio Vargas: Rio de Janeiro.

Costa, R. G. G., \& Rezende, J. F. C. (2018). Strategic alignment of knowledge management and value creation: implications on to an oil and gas corporation. RAUSP Management Journal, 53(2), 241-252. https://doi.org/10.1016/j.rauspm.2017.11.001

Curado, C., Oliveira, M., Maçada, A. C. G., \& Nodari, F. (2017). Teams' innovation: getting there through knowledge sharing and absorptive capacity. Knowledge Management Research \& Practice, 15(1), 45-53. https://doi.org/10.1057/kmrp.2015.8

Darroch, J ., \& McNaughton, R. (2003). Beyond market orientation: Knowledge management and the innovativeness of New Zealand firms. European Journal of Marketing, 37(3-4), 572-593. https://doi.org/10.1108/03090560310459096

Feil, A. A., \& Schreiber, D. (2017). Sustentabilidade e desenvolvimento sustentável: desvendando as sobreposições e alcances de seus significados. Cadernos EBAPE.BR, 14(3), 667-681. http://dx.doi.org/10.1590/1679-395157473

Francini, W. S. (2002). A gestão do conhecimento: Conectando estratégia e valor para a empresa. RAE eléctron., 1(2), 1-16. http://www.scielo.br/pdf/raeel/v1n2/v1n2a14

Gamerschlag, R. (2013). Value relevance of human capital information. Journal of Intellectual Capital, 14(2), 325-345. https://doi.org/10.1108/14691931311323913

Gogan, L. M., Artene, A., Sarca, I., \& Draghici, A. (2016). The Impact of Intellectual Capital on Organizational Performance. Procedia - Social and Behavioral Sciences, 221, 194-202. https://doi.org/10.1016/j.sbspro.2016.05.106

Gurteen, D. (1998). Knowledge, Creativity and Innovation. Journal of Knowledge Management, 2(1), 5-13. https://doi.org/10.1108/13673279810800744

Ipe, M. (2003). Knowledge Sharing in Organizations: A Conceptual Framework. Human Resource Development Review, 2(4), 337-359. https://doi.org/10.1177/1534484303257985

Kianto, A., Sáenz, J., \& Aramburu, N. (2017). Knowledge-based human resource management practices, intellectual capital and innovation. Journal of Business Research, 81, 11-20. https://doi.org/10.1016/j.jbusres.2017.07.018

Kogut, C. S., \& Mello, R. C. (2017). Reverse Knowledge Transfer in Multinational Companies: A Systematic Literature Review. Brazilian Administration Review, 14(1), 1-25. http://dx.doi.org/10.1590/18077692 bar2017160097

Kopnina, H. (2017). Sustainability: new strategic thinking for business. Environ Dev Sustain, 19(1), 27-43. https://doi.org/10.1007/s10668-015-9723-1

Kotler, P., \& Keller, K. L. (2012). Administração de marketing (14 ed.). Tradução de Sônia Midori Yamamoto; revisão técnica Edson Crescitelli. São Paulo: Pearson Education do Brasil.

Liao, S.-H., Chen, C.-C., Hu, D.-C., Chung, Y.-C., \& Yang, M.-J . (2017). Developing a sustainable competitive advantage: absorptive capacity, knowledge transfer and organizational learning. Journal of Technology Transfer, 42(6), 1431-1450. https://doi.org/10.1007/s10961-016-9532-1

Liao, S.-H., \& Hu, T.-C. (2007). Knowledge transfer and competitive advantage on environmental uncertainty: An empirical study of the Taiwan semiconductor industry. Technovation, 27(6-7), 402-411. https://doi.org/10.1016/j.technovation.2007.02.005

Martelo-Landroguez, S., \& Cepeda-Carrión, G. (2016). How knowledge management processes can create and capture value for firms? Knowledge Management Research \& Practice, 14(4), 423-433. https://doi.org/10.1057/kmrp.2015.26

McDowell, W. C., Peake, W. O., Coder, L., \& Harris, M. L. (2018). Building small firm performance through intellectual capital development: Exploring innovation as the "black box". Journal of Business Research, 88, 321-327. https://doi.org/10.1016/j.jbusres.2018.01.025

Meneghetti, F. K. (2011). O que é um ensaio-teórico? Revista de Administração Contemporânea, 15(2), 320332. http://dx.doi.org/10.1590/S1415-65552011000200010

Motta, V. C. (2008). Ideologias do capital humano e do capital social: da integração à inserção e ao conformismo. Trab. educ. saúde, 6(3), 549-572. http://dx.doi.org/10.1590/\$1981-77462008000300009

Munck, L., Galleli, B., \& Souza, R. B. (2012). Níveis de entrega das competências de suporte à ecoeficiência organizacional: um estudo de caso em uma indústria do setor eletroeletrônico. Revista Brasileira de Gestão de Negócios, 14(44), 274-292. https://rbgn.fecap.br/RBGN/article/viewFile/948/885 
Nascimento, L. S. (2018). Uma Reflexão Acerca da Relação entre Sustentabilidade e Estratégia Organizacional. In Poisson (Org.), Sustentabilidade e Responsabilidade Social em Foco (Vol. 5). Belo Horizonte: Poisson. ISBN: 978-85-93729-65-2. Disponível em: http://poisson.com.br/bs/produto/sustentabilidade-eresponsabilidade-social-em-foco-volume-5/

Pereira, M. F. (2003). A gestão organizacional em busca do comportamento holístico. In Angeloni, M. T. (Coord.), Organizações do conhecimento: infra-estrutura, pessoas e tecnologias. São Paulo: Saraiva.

Radaelli, G., Mura, M., Spiller, N., \& Lettieri, E. (2011). Intellectual capital and knowledge sharing: the mediating role of organisational knowledge sharing climate. Knowledge Management Research \& Practice, 9(4), 342-352. https://doi.org/10.1057/kmrp.2011.29

Rezende, Y. (2002). Informação para negócios: os novos agentes do conhecimento e a gestão do capital intelectual. Ci. Inf., 31(1), 75-83. http://dx.doi.org/10.1590/S0100-19652002000100008

Rother, E. D. (2007). Revisão Sistemática X Revisão Narrativa. Acta Paul Enferm, 20(2), v-vi. http://dx.doi.org/10.1590/S0103-21002007000200001

Runyan, R., Droge, C., \& Swinney, J. (2008). Entrepreneurial Orientation versus Small Business Orientation: What Are Their Relationships to Firm Performance? Journal of Small Business Management, 46(4), 567588. https://doi.org/10.1111/j.1540-627X.2008.00257.x

Sardo, F., Serrasqueiro, Z., \& Alves, H. (2018). On the relationship between intellectual capital and financial performance: A panel data analysis on SME hotels. International Journal of Hospitality Management, 75, 67-74. https://doi.org/10.1016/j.jijhm.2018.03.001

Savitz, A. W., \& Weber, K. (2007). A empresa sustentável: o verdadeiro sucesso é o lucro com responsabilidade social e ambiental. Tradução de Afonso Celso da Cunha Serra. Rio de Janeiro: Elsevier.

Seghezzo, L. (2009). The five dimensions of sustainability. Environmental Politics, 18(4), 539-556. https://doi.org/10.1080/09644010903063669

Serenko, A., Bontis, N., \& Hull, E. (2016). An application of the knowledge management maturity model: the case of credit unions. Knowledge Management Research \& Practice, 14(3), 338-352. https://doi.org/10.1057/kmrp.2014.37

Shahzad, K., Bajwa, S. U., Siddiqi, A. F. I., Ahmid, F., \& Sultani, A. Z. (2016). Integrating knowledge management (KM) strategies and processes to enhance organizational creativity and performance: an empirical investigation. Journal of Modelling in Management, 11(1), 154-179. https://doi.org/10.1108/J M2-07-20140061.

Silva, M. G., Araújo, N. M. S., \& Santos, J. S. (2012). “Consumo consciente": o ecocapitalismo como Ideologia. Revista Katálysis, 15(1), 95-111. http://www.scielo.br/pdf/rk/v15n1/a10v15n1.pdf

Silva, M. E., \& Cândido, G. A. (2014). The business contribution for sustainable consumption: a proposal of theoretical categories and analytical parameters. Revista Eletrônica de Ciência Administrativa, 13(1), 7488. https://doi.org/10.21529/RECADM.2014004

Stefano, N. M., \& Laux, R. O. (2017). Sustentabilidade empresarial por meio do sistema de gestão integrada (SGI). Sustainable Business International Journal, 70, 1-25.

Stewart, T. A. (1998). Capital Intelectual: a nova vantagem competitiva nas empresas. Trad. Ana Beatriz Rodrigues, Priscilla Martins Celeste. Rio de J aneiro: Campus.

Subramaniam, M., \& Youndt, M. A. (2005). The Influence of Intellectual Capital on the Types of Innovative Capabilities. Academy of Management Journal, 48(3), 450-463. https://doi.org/10.5465/amj.2005.17407911

Sveiby, K. E. (1998). A nova riqueza das organizações. Trad. Luiz Euclydes Trindade Frazão Filho. Rio de Janeiro: Campus.

Teh, P.-L., \& Yong, C.-C. (2011). Knowledge Sharing in is Personnel: Organizational Behavior's Perspective. Journal of Computer Information Systems, 51(4), 11-21. https://www.tandfonline.com/doi/abs/10.1080/08874417.2011.11645497

Tonet, H. (2008). 0 desafio de compartilhar e disseminar conhecimento nas organizações. In: Angeloni, M. T. (Org.), Gestão do conhecimento no Brasil: casos, experiências e práticas de empresas privadas. Rio de Janeiro: Qualitymark.

Wojahn, R. M., Rados, G. J. V., \& Trzeciak, D. S. (2017). Conhecimento, criatividade e desempenho organizacional: estudo em empresas de tecnologia da informação e comunicação. Revista Eletrônica de Ciência Administrativa, 16(3), 213-232. http://dx.doi.org/10.21529/RECADM.2017013

Zack, M. H. (1999). Managing codified knowledge. Sloan Management Review, 40, 45-58. 